\title{
FAMÍLIA E ESCOLA: UMA PARCERIA COM SUCESSO SEM INVERSÕES DE PAPÉIS
}

\author{
Lívia Carolina Viana dos Santos Valenziano*
}

\begin{abstract}
RESUMO: Este artigo tem como objetivo discutir e obter elementos de análise sobre a constituição e características da Família e Escola para uma reflexão do papel dos pais e da família na educação do ser humano atualmente. O método que será utilizado neste trabalho é a revisão bibliográfica, que é indicada a fim de proporcionar uma visão sobre o tema escolhido, apresentando-o de forma clara e objetiva. Sabemos que hoje em dia há uma grande discussão entre duas instituições: Família e Escola, discussão que vem girando em torno de papéis e funções para quem são estabelecidas. As formações familiares se modificaram ao longo dos anos em decorrência da modernização e desenvolvimento da sociedade.
\end{abstract}

Palavras-chave: Família; Escola; Relações; Troca de papéis.

ABSTRACT: This paper aims to discuss and get analysis of elements of the constitution and characteristics of Family and School to reflect the role of parents and family in education of human beings today. The method that will be used in this work is the literature review, which is indicated to provide an insight into the chosen topic, presenting it in a clear and objective way. We know that today there is a big argument between two institutions: Family and School, discussion next turning around roles and functions for those who are established. Family formations have changed over the years due to the modernization and development of society.

Keywords: Family; School; Relationships; Exchange roles.

\section{INTRODUÇÃO}

Este artigo tem como objetivo discutir e analisar o papel da família e da escola na educação e vida do indivíduo. É relevante, também, por apontar as razões da troca de responsabilidades entre família e escola e pelo fato de que vivo essa experiência, cotidianamente, na Educação Infantil. Nessa troca de papéis que acontece entre família e escola, a escola tem cumprido o papel da

\footnotetext{
"Graduada em Pedagogia, com licenciatura plena pelo Centro Universitário Barão de Mauá (2010). Especialista em Educação Infantil e Alfabetização pelo Centro Universitário Claretiano (2013). Pós-graduanda em Pedagogia Empresarial pelo Centro Universitário Claretiano (2015). Coordenadora do Ensino Fundamental II no Colégio Renovatus, Campinas (SP).
} 
família.

O método que utilizaremos neste trabalho é a revisão bibliográfica, indicada a fim de proporcionar uma visão sobre o tema escolhido, apresentando-o de forma clara e objetiva.

Em primeiro lugar, abordaremos a história da família e suas configurações, mostrando sua definição e seus papéis perante a sociedade. Apresentaremos autores que tratam dessa definição.

Em segundo lugar, apresentaremos uma visão de como pode ocorrer a parceria entre família e escola sem que haja uma inversão de papéis.

É muito comum, hoje, ouvirmos que os pais perderam a autoridade sobre os filhos e que não existe mais respeito nessa relação. Mas por que será que isso mudou, como, quando? Aqui também abordaremos esse assunto.

As famílias começaram a se dar conta de que estão ficando sem tempo para estarem, cuidarem de seus filhos, cada vez mais, por conta de sua rotina. E onde isso começa a prejudicar a escola?

Normalmente, o que se vê, é que devido a grande ausência dos pais na vida escolar dos filhos, estes começam a apresentar comportamentos agressivos, entre outros. Então, os pais começam a se perguntar: "o que está acontecendo, será que foi algo na escola?", sem se darem conta de que esse comportamento, e todos os outros, é decorrente da ausência, falta de carinho, afeto, etc.

Esperamos que, ao analisarmos as duas grandes instituições, Família e Escola, possamos contribuir destacando a necessidade de educadores e famílias se posicionarem, cada um cumprindo, adequadamente, seus papéis, para que não haja essa troca.

\section{A FAMÍLIA E SUAS CONFIGURAÇÕES ATUAIS}

De acordo com Rodrigues, Sobrinho e Silva (2000), a família pode ser definida como um grupo de pessoas ligadas por laços sanguíneos e também por sentimentos de integração nesse grupo, ou seja, são "membros da família".

A família é formada por pessoas que interagem por diversos motivos, dentre eles, afetividade e reprodução, dentro de um processo histórico de vida, mesmo 
não habitando o mesmo espaço físico, assim sendo, "a família se desenvolve compartilhando uma relação social dinâmica, a partir de um sistema de crenças, valores e normas, estruturados na cultura da família, conforme a classe social na qual está inserida," (PATRíCIO, 1994).

Segundo Oliveira e Simionato (2003), significativas mudanças ocorreram na sociedade brasileira e as famílias têm sofrido fortíssimas influências de questões políticas, econômicas, sociais e culturais, que consequentemente acarretam em mudanças nos papéis e nas relações. Para as autoras, na sociedade rural predominava a família patriarcal que era fechada em si mesma, que não sofria interferências pela sociedade de fora, mas, com o passar dos tempos, tudo isso foi se modificando e a família passa ser modificada por uma série de questões.

No final década de 60 o número de separações e divórcios foi crescendo e a religião foi perdendo sua força, não conseguindo mais sustentar casamentos quando as relações passavam a enfrentar complicações. A partir daí, começaram a surgir inúmeras organizações familiares: as pessoas se casam sucessivamente e, consequentemente, uma mesma mãe, gera filhos de pais diferentes; casais homossexuais adotando filhos legalmente; "produções independentes" começam a surgir com mais frequência; e, mais ultimamente, duplas de mães solteiras ou já separadas compartilham a criação de seus filhos. (OLIVEIRA, SIMIONATO, 2003)

Sabemos que as formações familiares são profundamente influenciadas por velhos costumes, hábitos dos séculos passados que deixam traços nas famílias dos tempos de hoje, chamada então de família "pós-moderna" (ROUDINESCO apud GARCIA, 2003).

Segundo Roudinesco (2003, p.10) "a vida familiar apresenta-se, praticamente, em todas as sociedades humanas, mesmo naquelas cujos hábitos sexuais e educativos são muito distantes dos nossos". Roudinesco (2003, p. 12) nos mostra três tipos de períodos na evolução da família:

Numa primeira fase, a família dita "tradicional" serve acima de tudo para assegurar a transmissão de um patrimônio. Os casamentos são então arranjados entre os pais sem que a vida sexual e afetiva dos futuros esposos, em geral unidos em idade 
precoce, seja levada em conta. Nessa ótica, a célula familiar repousa em uma ordem do mundo imutável e inteiramente submetida a uma autoridade patriarcal, verdadeira transposição da monarquia de direito divino. Numa segunda fase, a família dita "moderna" torna-se o receptáculo de uma lógica afetiva cujo modelo se impõe entre o final do século XVIII e meados do XX. Fundada no amor romântico, ela sanciona a reciprocidade dos sentimentos e os desejos carnais por intermédio do casamento. Mas valoriza também a divisão do trabalho entre os esposos, fazendo ao mesmo tempo do filho um sujeito cuja educação sua nação é encarregada de assegurar. A atribuição da autoridade torna-se então motivo de uma divisão incessante entre o Estado e os pais, de um lado, e entre os pais e as mães, de outro. Finalmente, a partir dos anos 1960, impõe-se a família dita "contemporânea" — ou "pós-moderna" —, que une, ao longo de uma duração relativa, dois indivíduos em busca de relações íntimas ou realização sexual. A transmissão da autoridade vai se tornando então cada vez mais problemática à medida que divórcios, separações e recomposições conjugais aumentam. (ROUDINESCO, 2003, p.12)

Sabemos que hoje as famílias não são mais denominadas assim por diversos motivos, que provocam alterações e por isso acabam se desfazendo.

Família saudável é definida por Elsen (1994) como sendo aquela que se valoriza, que tem amor próprio, na qual as pessoas que nela convivem se sentem amparados e acolhidos por essa instituição. Em sua estrutura e organização permite que os integrantes possam juntos estabelecer os mesmos objetivos e fornecem meios para que haja desenvolvimento, saúde e bem-estar a todos aqueles que ali estão presentes.

Segundo Rodrigues, Sobrinho e Silva (2000, p.20) "toda família tem sua significação própria, especial, indefinível. Simplesmente, ela existe, se mostra, podendo se apresentar sob as mais variadas dimensões". E como lembra Szymanski

O processo de socialização se dá no convívio familiar e, em especial, por meio das práticas educativas desenvolvidas com a finalidade de transmitir hábitos, valores, crenças e conhecimentos que se acredita serem úteis para a inserção dos filhos na sociedade. (SZYMANSKI, p. 6, 2004). 
Neste contexto, família, Rodrigues, Sobrinho e Silva (2000, v. 2, p. 20) afirmam que existem vários tipos de configurações de família, são elas:

Família nuclear, também chamada de biparental, composta pelo pai, mãe e filhos. Família associativa, quando incluídos entre os membros, está também às pessoas com as quais são mantidos estreitos laços afetivos (CARTANA apud ELSEN, 1994); Família adotiva atribuiu esta denominação ao conjunto de pessoas que, ao se encontrarem, desenvolvem afinidade, passam a conviver considerando-se uma mesma família, independente de qualquer consanguinidade, tendo-se, por exemplo: estudantes que vivem em residências universitárias ou que dividem apartamento ou outros espaços residenciais; Família dual ou monoparental, aqui denominada como aquela formada apenas por dois membros: mãe-filho, pai-filho, esposo-esposa/ companheiro-companheira; Família ampliada, emprestaremos esta denominação ao tipo de família ao qual Patrício, (1994), citando Spiro, diz formar-se sem a necessidade de haver espaço físico comum, nem de serem desempenhadas todas as funções tradicionais em conjunto. Os indivíduos se consideram como parentes, "psicologicamente falando"; Família recomposta, denominação esta atribuída por nós, àquela família (marido, esposa e filhos ou um dos cônjuges e filhos), que após uma primeira experiência não bem sucedida, faz uma nova tentativa com o mesmo ou com outro cônjuge; Família homossexual resulta da união de pessoas do mesmo sexo. (RODRIGUES, SOBRINHO, SILVA, 2000, v. 2, p. 20).

Toda opção pelo estilo de família a ser adotado por um indivíduo está ligada às experiências culturais e familiares que vivenciam, incluindo conhecimentos, crenças e valores adquiridos, circunstâncias de vida e às próprias dificuldades.

Cada indivíduo do núcleo familiar é um ator e este tem uma incumbência, uma função, e uma das funções dos indivíduos da família é dar proteção aos seus membros, física e emocional. Essa é uma regra básica em toda e qualquer sociedade. Para Garcia (2005), compete à família assegurar aos seus membros com bem-estar material, emocional, favorecendo um ambiente agradável, educando e ensinando valores morais. Esses valores morais, culturais, cívicos, materiais etc., precisam ser transmitidos não só, através da instrução familiar 
primeiramente, mas através, também, de uma instituição escolar.

Com todas as mudanças que vem sofrendo ao longo da história, as famílias começaram a se preocupar com o dia a dia da criança. Essas discussões sobre família nos tempos atuais não estão somente nas relações sociais, estão presentes também no âmbito escolar.

A partir de 1990, com a instituição do Estatuto da Criança e do Adolescente - ECA, que torna a criança um sujeito de direitos, é direito adquirido da criança, ir à escola, ter acesso à educação como medida de proteção, obrigando as famílias e o Estado garantir que esse direito seja cumprido.

Muito se fala em parceria entre escola e família, mas, nos últimos anos estamos observando que essa parceria não está acontecendo, mas sim uma troca de papéis, onde a Escola cumpre deveres que, teoricamente, seriam da família, onde a escola mais "cuida" do que "educa". Para que isso não aconteça a escola precisa ter postura profissional. A seguir, veremos como essas relações entre família escola estão estabelecidas.

\section{FAMÍLIA E ESCOLA: QUEM CUIDA? QUEM EDUCA?}

Vimos anteriormente, conceitos relacionados à família e relatamos sua evolução, suas concepções desde o inicio até os dias de hoje, na sociedade em geral.

Nos tempos de hoje é normal dizer que "os pais não tem mais autoridade sobre seus filhos" ou "os filhos não tem o mesmo respeito com os pais como se tinha antigamente".

Em um livro chamado Educação na família ou na escola, o que é como se faz, o autor pontua que, na relação entre mãe e pai, constantemente trocam acusações como cada um trata os filhos, ficam tentando encontrar quem é mais permissível, quem é o mais tolerante. Ao mesmo tempo, a escola se volta contra a família porque tem que suprir a ausência da falta de respeito. (LÓPEZ, 2002, p. 13)

Sabemos que, para que se tenha um bom desenvolvimento escolar, é necessário, principalmente, respeito mútuo entre as pessoas que estão 
interagindo. Quando isso não acontece, há uma série de consequências, como mau comportamento do aluno na escola, falta de respeito com pessoas que 0 cercam, etc, e quando tudo isso foge ao controle da escola os educadores passam, então, a chamar os pais para "ajudar" a solucionar esse problema.

Muito se fala hoje, na área da educação, em uma relação entre a escola e família, pontuando uma parceria entre ambas, mas, tanto a escola quanto a família precisam ter clareza sobre o que querem e como podem trabalhar juntas, sem que nenhuma dessas instituições interfira no trabalho da outra.

Em um livro de Perrenoud (2000), Dez Novas Competências para Ensinar, o autor apresenta uma definição sobre competência. Para o autor, a família ocupa um lugar, têm outras perspectivas, outras preocupações diferentes das da escola e, assim como a família, a escola tem perspectivas e tarefas a cumprir. Perrenoud (2000) ainda afirma que "a competência dos professores consiste em aceitar os pais como eles são em sua diversidade". (PERRENOUD, 2000, p. 117 apud GARCIA, 2005). Fundamentando o conceito de competência o autor afirma que:

A parceria é uma construção permanentemente, que se operará melhor se os professores aceitarem tomar essa iniciativa sem monopolizar essa discussão, dando provas de serenidade coletiva, encarnando-a em alguns espaços permanentes, admitindo uma dose de incerteza e de conflito e aceitando a necessidade de instâncias de regulação.

Na maioria dos casos, infelizmente, essa parceria não se faz, pois a escola acaba cumprindo deveres que cabem à família. Não há coordenação entre família e escola, não há enfrentamento e resolução de problemas, e, no final das contas, o aluno, que deveria ter primazia, é o maior prejudicado dessa descoordenação.

Em minha vivência escolar, sempre me incomodou, quando os alunos chegam à escola e os pais dizem "olha, eu não escovei os dentes dele(a) e ainda está de pijama; você troca, por favor?" ou "eu não fiz a lição de casa com ele(a), você faz aí?", enfim, são questões onde a escola pede uma parceria da família e não a tem. A quem cabe os cuidados pessoais, o dever de casa, por exemplo, da criança, Escola ou Família? 
Pensando ainda no dever de casa, Carvalho (2004) conclui que a lição que vai para casa "é considerada uma estratégia de ensino: de fixação, revisão, reforço e uma preparação do aluno para provas e aulas, na forma de leitura e exercícios" (CARVALHO, 2004, n²5).

Realmente quando a lição da escola vai para casa, visa-se preparar o aluno, dar continuidade no conteúdo que foi aplicado na escola, e pensando na educação infantil, onde as crianças necessitam de ajuda para realizar tal lição, quando a mesma não acontece, esse ensinamento foi "quebrado". Isso acarreta uma série de fatores: baixa participação em sala de aula, vergonha por não ter realizado a lição, entre outros. Sendo assim, pensando na coordenação entre escola e família, podemos definir que a não participação dos pais na atividade de lição de casa, não é uma parceria entre escola e família.

Carvalho ainda afirma que:

O dever de casa não apenas afeta o seu planejamento e implementação, e, portanto, o trabalho docente, mas afeta também a vida dos estudantes fora da escola e sua rotina familiar, pois, supõe a conexão entre as atividades de sala de aula e de casa a uma estrutura adequada apoiando as atividades escolares. (CARVALHO, 2004, p.95).

Assis e Vinha (2005, p.2) afirmam que, na nossa sociedade existem duas instituições formalmente responsáveis pela educação do ser humano: a família e a escola. Cada uma dessas instituições tem um caráter diferenciado, objetivos diversos, mas com uma mesma essência, educar: na família o indivíduo aprende em um espaço privado, na escola o aluno aprende em grupo.

$\mathrm{Na}$ escola existe um espaço muito adequado e organizado para receber os alunos. Na rotina escolar acontecem diversas coisas, inclusive conflitos, que, quando fogem ao controle, a família é chamada para um diálogo e, juntos, tentarem traçar um plano de ação, buscando possíveis fatores que determinaram o mal comportamento. Entretanto, por vergonha, o que acontece na maioria das vezes, as famílias omitem fatos, quando há questões muito íntimas do núcleo familiar.

Não podemos nos esquecer de que quando a escola convoca as 
famílias para uma conversa, está se sentirá em uma posição bastante desconfortável, constrangedora até, por vezes, pois ouvirá que seu filho não está se comportando. Por isso, é dever da escola se posicionar, mostrar a essa família que a oportunidade que estão tendo de conversar é para procurarem, juntos, caminhos, soluções. (ASSIS, VINHA 2005).

As autoras ainda afirmam que:

Cabe ao professor ouvir, ampará-los e não incentivar a discórdia ou os ressentimentos já existentes, quando os pais quiserem conselhos eles mesmos solicitarão, e quando o professor os der, é importante, inicialmente, reconhecer que ninguém realmente tem as respostas e o que se pode fazer é somente concordar em experimentar diferentes estratégias e procedimentos mais coerentes com o desenvolvimento sócioafetivo da criança e que sejam propícios, ou melhor, que caminhem na direção do atendimento as necessidades que ela tem de fato. Se o professor puder acolher e conquistar os pais, irá perceber que sempre poderá contar com eles na maioria das vezes. (ASSIS, VINHA, 2005, p.15).

Para que não haja esse tipo de relação entre essas instituições, a escola precisa ter claro qual é o seu papel na sociedade e ter profissionalismo, sendo assim, as famílias também precisam entender o seu papel na vida da criança, para que assim, ambos os trabalhos, sejam eficazes e de qualidade.

Podemos elencar algumas ações, realizadas pelas famílias, para que haja parceria entre família e escola:

- Participar de reunião escolar;

- Olhar agendas e responder quando solicitado;

- Estar atento ao comportamento dos filhos;

- Quando solicitados, comparecer e não omitir fatos e nem julgar atitudes;

- Não transferir responsabilidades à escola que é de sua competência (família).

- Levar com pontualidade as aulas para que não haja interferência no aprendizado. 
- "Punir" os filhos com sabedoria quando necessário, e não, simplesmente, chegar à escola e dizer: "hoje ele não se comportou, conversa com ele".

- Falar bem da escola para os filhos.

- Procurar saber como foi o dia na escola, isso ressalta para a criança sua importância.

- Conhecer o professor e conversar com ele sobre quaisquer angústias que forem surgindo durante 0 ano, isso gera uma relação saudável e de confiança.

Embora saibamos que as duas têm um papel fundamental na formação do indivíduo e a responsabilidade de prepará-lo para um futuro cidadão de bem, a escola e a família precisam ter em mente bem definido qual é o seu papel. Enquanto a escola contribui com o desenvolvimento do indivíduo, mais especificamente na aquisição do saber em áreas distintas do conhecimento, um agente transformador na sociedade, a família tem como obrigação educá-lo moralmente, buscando compreender e ajudar nas necessidades que forem surgindo. (DESSEN, POLONIA, 2005).

Segundo Dessen e Polonia (2005 apud SZYMANSKY, 2001) "as ações educativas na família e na escola apresentam funções distintas quanto aos objetivos, conteúdos, métodos, bem como as expectativas e interações peculiares a cada contexto". Mesmo assim, vivemos numa constante de troca de papéis entre as duas instituições. A escola muito cobra uma parceria dos pais, mas será que ela também está cumprindo com seu papel? Ou simplesmente transfere questões para família que é de sua competência?

$\mathrm{Na}$ rotina escolar sabemos que "problemas" com alunos em sala de aula acontecem com frequência. É fato que, normalmente, os educadores encaminham os alunos para que outra pessoa resolva. Ele é levado à diretoria, coordenação, entre outros. Quando essas autoridades não conseguem resolver, então a escola convoca a família. Neste momento, o educador acaba perdendo autoridade/credibilidade com seu aluno, pois, está transferindo um problema que seria de sua competência resolver. Assis e Vinha (2005) afirmam que essa "é uma maneira, de certa forma cômoda, de o professor ou a escola 
resolver problemas".

Realmente, as instituições não conseguem e não têm claro quais são seus papéis, pois, é como se o professor estivesse "abandonando" suas funções que, dentre elas, seria auxiliar o aluno a resolver seus problemas. Agindo dessa maneira a visão que o professor transmite é: "o problema não é meu", ou, "eu não tenho obrigação de resolver esse tipo de problema", ou ainda, "não posso atrapalhar minha aula por indisciplinaridade de alunos", afirmam Assis e Vinha (2005, p.2).

Segundo entrevista dada por Rosely Sayão (BARROS, 2011) há uma série de fatores voltados para a falta de vínculos entre escola e educação.

Sobre a crítica que os educadores e a escola fazem sobre a falta de transmissão de valores da família, Sayão argumenta que a escola não tem razão, e "talvez, seja de responsabilidade da escola, pois, começamos a chamar as famílias a participar do processo escolar sem saber o que estávamos fazendo [...], desvirtuamos as duas instituições: a escola se tornou mais familiar, e a família mais escolar, convocamos os pais e não sabemos o que fazer com eles". (BARROS, 2009)

Fazemos uma crítica a Sayão quando esta coloca que "[...] talvez seja de responsabilidade da escola inserir valores [...]", pois, é função da família educar moralmente o indivíduo, para que este seja um cidadão com princípios e atitudes corretas; ficaria muito cômodo para as famílias transferir essa função. (BARROS, 2009)

Na mesma entrevista, Sayão responde sobre "o que é ser profissional":

"[...] temos pouca fundamentação teórica no que diz respeito às metodologias a serem usadas nas escolas. Um exemplo, brincar é importante na primeira infância [...] não é qualquer brincar, porque, senão, qual é a diferença entre brincar na escola ou em casa? Outro ponto colocado é a questão de se chamar de tia, torna-se um ambiente bem familiar, muitos professores não tem ideia de quanto isso interfere na relação escolar. (BARROS, 2009).

O que se tem observado é que está havendo uma contradição nas intervenções com os indivíduos no que diz respeito a orientações, é muito 
importante que as duas instituições saibam, mutuamente, quais os objetivos e funções de ambas.

É sabido que é função da família a boa estruturação do indivíduo, que desde o nascimento, e por toda a vida, precisa ser assistido, cuidado, amado. É na família que ele inicia seu desenvolvimento e crescerá, aprenderá, construirá sua identidade, formará sua personalidade a partir de exemplos que recebe de seus pais, portanto, a escola não consegue assumir essa tarefa (ASSIS, VINHA, 2005). Por isso, então, vemos um grande embate entre as partes, uma culpabilizando a outra, delegando as responsabilidades uma para a outra, tanto escola quanto família. Não se têm claras as funções e papéis, a escola não lida com o indivíduo aluno e a família não lida com o individuo filho.

A seguir, algumas ações, realizadas pela escola, que podem contribuir para uma interação/integração, saudável, entre a escola e a família.

- Conhecer as famílias dos alunos e fazer com que se sintam integrados à escola;

- Observar atitudes e rotina dos alunos, sem julgar e interferir, e só recorrer à família quando realmente necessário;

- Compartilhar com as famílias as conquistas dos alunos e não só as dificuldades;

- Aceitar as diferentes constituições familiares, pois, sabemos que existem pessoas que pensam e agem de diversas formas;

- A escola precisa estar aberta a receber elogios, críticas e sugestões.

Assim sendo, conforme Lopez (2002),

De modo geral, a participação dos pais deve se concretizar no auxílio à atuação pedagógica escolar. Isso implica propiciar a escola o suporte necessário para que educação escolar seja o fruto de coordenação e coerência entre as atuações dos professores e da família. Por parte da escola, essa participação dos pais deve ser considerada no próprio planejamento das tarefas que os professores realizam. 


\section{CONSIDERAÇÕES FINAIS}

Após leitura dos textos, conclui-se que entre as instituições, Escola e Família, não está claro, realmente, para ambas, quais são seus papéis. 0 "jogo de empurra" cria uma sucessão de enganos e desacertos na relação entre escola e família, onde o grande prejudicado é o aluno.

Analisando todo processo de relação que se estabeleceu entre escola e família ao longo do tempo, identificamos que em certos momentos essa relação foi caracterizada em função de determinantes sociais e, em outros, em função de aspectos psicológicos da família.

De forma geral, esta relação sempre esteve marcada por movimentos onde um culpa o outro pela ausência de responsabilidade compartilhada. Há forte ênfase em situações-problema que ocorrem no contexto escolar e certa falta de profissionalismo por parte da escola, que muitas vezes responsabiliza o aluno ou a família pelo mau comportamento ou desempenho.

Para que Família e Escola tenham uma boa relação é preciso que ambas dialoguem constantemente, estejam abertas a sugestões, críticas, etc.; que a escola compreenda as diferentes dinâmicas familiares.

Participar significa ouvir e expor opiniões, propor ações que envolvam todas as partes do processo de ensino-aprendizagem. Isso implica também a escola refletir sobre suas práticas, ao invés de só convocar os pais em situações que não andam bem, ou seja, mau comportamento, nota baixa tudo que envolva pontos negativos dos alunos.

Vale lembrar que família e escola tem um papel fundamental na construção de identidade e autonomia, e quando o envolvido, filho-aluno, se sente amparado e seguro por essas instituições, concluímos que só tende a favorecer no processo ensino-aprendizagem.

Cabe à escola procurar os métodos mais adequados para aproximar os pais e ajudá-los a compreender quão importante é sua participação na vida escolar dos filhos.

Podemos constatar que, quanto maior a abertura para que a família conheça o trabalho desenvolvido pela escola, maior será o interesse e a 
participação dos pais na vida escolar dos filhos.

\section{REFERÊNCIAS BIBLIOGRÁFICAS}

ASSIS, O. Z. M; VINHA T. P. Compartilhar ou transferir as responsabilidades? Considerações sobre a relação entre escola e família. Anais do XII Encontro Nacional de professores do Proepe: Educação e cidadania. Campinas, SP: Faculdade de Educação DA UNICAMP, 2005, p.15-32.

BARROS, R. Falta de vínculos. Revista Educação. São Paulo, v.1, n. 1, p.4-7, 2009.

CARVALHO, M.E.P. Escola como extensão da família ou família como extensão da escola? $O$ dever de casa e as relações família-escola. João Pessoa: Universidade Federal da Paraíba, Centro de Educação, n.25, 2004.

GARCIA, H. G. O. Família e escola na educação infantil: um estudo sobre reuniões de pais. Dissertação (Mestrado em Psicologia) - Universidade de São Paulo, São Paulo, 2005.

LÓPEZ, J. S. Educação na família e na escola: o que é como e se faz. Trad. Milton Camargo Mota. São Paulo: Loyola, 2002.

POLONIA, A. C; DESSEN, M. A. Em busca de uma compreensão das relações entre família escola. Psicologia Escolar e Educacional, v.9, n.2,2005.

ROUDINESCO. E. A família em desordem. Trad. André Telles. Rio de Janeiro: Jorge Zahar, 2003.

RODRIGUES, M. S. P.; SOBRINHO, E. H. G; SILVA, R. M. A família e sua importância na formação do cidadão. Família, Saúde, Desenvolvimento, Curitiba, v.2, n.2, 2000, p.40-48.

SIMIONATO, M. A. W; OLIVERIA, R. G. Funções e transformações da família ao longo do ano. I Encontro Paranaense de Psicopedagogia da ABPPPR. Universidade Estadual de Maringá, Departamento de Psicologia, 2003.

SZYMANSKI, H. Práticas educativas familiares: a família como foco de atenção psicoeducacional. Revista Estudos de Psicologia, Campinas, v. 21, n. 2, mai./ago. 2004, p. 5-16. 